\title{
Planeta ROODA 2.0: um olhar no desenvolvimento tecnológico do ambiente virtual social de aprendizagem
}

\author{
Patrícia Alejandra Behar, Cristina Alba Wildt Torrezzan, Augusto Simon \\ Programa de Pós-Graduação em Informática na Educação \\ Universidade Federal do Rio Grande do Sul (UFRGS) \\ Caixa Postal 5071 - 90.041-970 - Porto Alegre - RS - Brasil \\ pbehar@terra.com.br, crisaaw@yahoo.com.br,ucl_guto@yahoo.com.br
}

Resumo. A socialização da internet está gerando uma facilidade de acesso às informações e uma maior interação entre as pessoas, antes impossibilitada por limites culturais ou geográficos. A educação, por sua vez, precisa acompanhar essas modificações da sociedade, evitando tornar-se desatualizada. Desse modo, este artigo aborda a reestruturação técnica do ambiente virtual de aprendizagem Planeta Rooda, tendo como base a Web 2.0. O Planeta ROODA 2.0 visa unir a tecnologia da Web com a interação social e a autonomia do usuário para, mais que a simples comunicação de um conceito, possibilitar que o aluno construa e valorize a sua trajetória de aprendizagem.

Palavras-chave: Ambiente virtual de aprendizagem, Web 2.0, educação a distância, relação homem-máquina, aprendizagem.

\section{ROODA Planet 2.0: a look into the technological development of the social virtual learning environment}

Abstract. The socialization of internet has been making it easier for people to access information and interact with each other, which was very difficult because of cultural or geographic limits. Therefore, Education has to be aware of such changes in society to remain up-to-date. This study proposes the technical reworking of an e-learning environment of Planeta Rooda, based on Web 2.0, aiming to provide the formation of a knowledge net supported by the interaction between students and teachers of different schools, considering the user as an active part of that tool. The Planeta ROODA 2.0 aims to put Web technology, social interaction and user autonomy together in order to make students able to build up and valorize their learning processes.

Keywords: E-learning environment, Web 2.0, distance education, human-computer interaction, learning process.

\section{Introdução}

A sociedade atual, com a globalização, exige que as pessoas sejam ativas, competitivas, interligadas, preparadas para constantemente ultrapassar paradigmas. $\mathrm{Na}$ educação, a tecnologia digital está cada vez mais sendo aliada a funções administrativas: realização de matrículas, elaboração de provas, cadastro de alunos e professores, digitalização dos catálogos da biblioteca e ao funcionamento do sistema de segurança do prédio. Porém a rotina da sala de aula, na maioria das vezes, ainda é marcada pelo discurso oral do professor, a exemplificação no quadro negro e a realização dos exercícios indicados pelo livro texto - todas essas ações realizadas necessariamente nessa ordem e ocorrentes uma de cada vez. Constata-se então que a aplicação dos recursos 
digitais na sala de aula está ocorrendo de maneira mais lenta e cautelosa que em outros ambientes, pois se verifica que a metodologia tradicional de ensino não é suficiente para estruturar e apropriar-se de todas as funcionalidades das tecnologias digitais. Torna-se então necessário aplicar essas tecnologias digitais na sala de aula de modo a elas apoiarem a construção do conhecimento do aluno da mesma maneira que apóiam tantas atividades no mercado de trabalho, nas tarefas domésticas e nos momentos de lazer, sob pena da educação tornar-se alheia à evolução da sociedade.

Sob a perspectiva de oportunizar práticas educativas compatíveis com a nova geração digital, este artigo aborda a reestruturação do ambiente virtual Planeta Rooda, ainda em andamento, realizada com o objetivo de contemplar as novas possibilidades do software social. A intenção é propiciar interações e interatividades em que o usuário encontre liberdade suficiente para agir criticamente sobre os conteúdos estudados, construindo conhecimento.

\section{O Ambiente Virtual de Aprendizagem Planeta Rooda}

Ambiente virtual de aprendizagem (AVA) é um espaço na Internet constituído pelos sujeitos, pelas suas interações e pelas formas de comunicação que se estabelecem através de uma plataforma de software (infra-estrutura tecnológica composta pelas funcionalidades e interface gráfica), tendo como foco principal a aprendizagem (Behar, 2007). A utilização do AVA possibilita que o aluno interaja tanto com o sistema em busca de informações (através de recursos para publicação de material e transferência de dados) quanto com colegas e professores (através de funcionalidades síncronas e assíncronas). Além disso, o professor tem a oportunidade de realizar um acompanhamento mais personalizado de cada aluno a partir da análise da trajetória de cada um e de seus registros no referido ambiente virtual de aprendizagem. Eles podem apoiar tanto a educação a distância quanto a semi-presencial e presencial. Os AVAS possibilitam a interatividade do usuário com várias ferramentas digitais ao mesmo tempo, semelhante ao uso simultâneo de MSN, e-mail e bate-papo a que essa "geração digital" está acostumada. Essa expressão refere-se às pessoas que nasceram a partir do final da década de 80. No Brasil, tem-se utilizado o termo "nativos digitais". Essas expressões identificam uma geração que cresce numa sociedade fortemente apoiada pelas tecnologias digitais. São acostumadas desde criança a interagir com muitas informações ao mesmo tempo - através do celular, televisão, internet e dos jogos de computador desenvolvendo a capacidade de coordenar várias informações ao mesmo tempo. Desse modo, dependendo da metodologia pedagógica aplicada, os ambientes virtuais de aprendizagem permitem que o aluno administre, de maneira autônoma, várias fontes de informações e diferentes ferramentas em prol de seus objetivos. A realização de batepapos com a turma, em especial, demonstra-se uma prática inovatória (em sala de aula) e com muitos pontos positivos. Embora num primeiro instante possa transmitir uma idéia de caos desenfreiado, logo verifica-se que na realidade possibilita que todos expressem a sua opinião sobre o assunto em questão. Principalmente aqueles alunos mais tímidos que não se manifestariam numa conversa presencial, demonstram-se muito participativos, desenvolvendo habilidades sociais. Alguns educadores estranham não conseguir acompanhar todos os diálogos durante o bate-papo, argumentando que isso não aconteceria se a conversa fosse presencial. Realmente não ocorreria, pois presencialmente apenas uma pessoa fala de cada vez e nem todos os alunos conseguem participar da 
discussão. Poucos falam, muitos apenas escutam. É justamente essa a grande vantagem da aplicação do bate-papo e outras ferramentas assíncronas como o fórum de discussões na sala de aula - possibilitar a colaboração de todos os alunos. Os diálogos ocorrerão em pequenos grupos, como em festas presenciais (ninguém tem acesso ao que todos conversam, mas todos participam). A diferença é que se pode salvar os diálogos, o que possibilita a leitura e análise de cada aluno.

Voltado a essas questões educacionais, o ambiente virtual de aprendizagem Planeta ROODA foi construído para apoiar a educação infantil e o ensino fundamental. Caracterizando-se pela temática espacial (figura 1), possibilita a configuração da interface gráfica pelo usuário e a opção de selecionar as ferramentas que mais se adaptam a sua metodologia de trabalho: comunicação síncrona, através das ferramentas de bate-papo e o Comunicador; comunicação assíncrona, como o Fórum; o trabalho coletivo, através da ferramenta Projetos; e publicação de arquivos, na Biblioteca. O Planeta Rooda encontra-se disponível em http://www.nuted.edu.ufrgs.br/planeta.
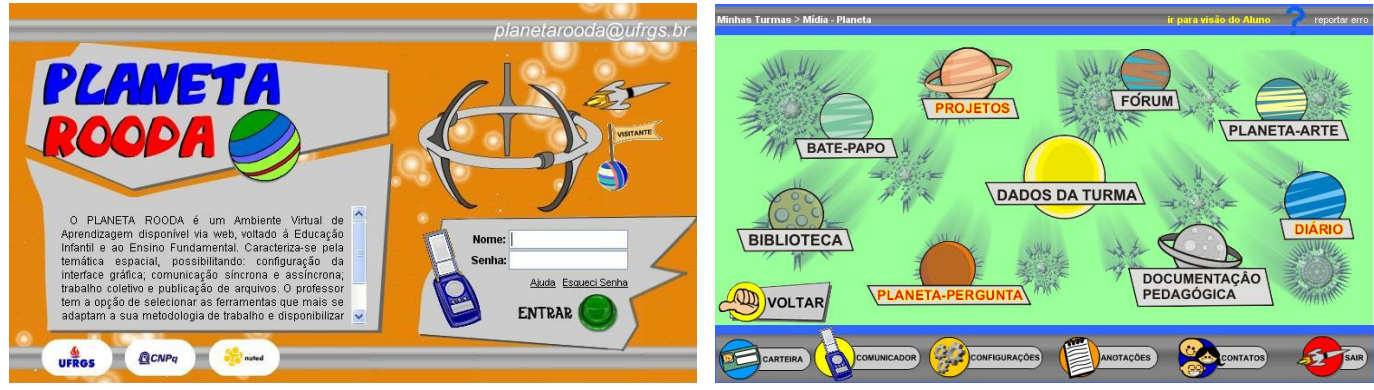

Figura 1 - Telas: login e inicial do Planeta ROODA

Atualmente, esse AVA funciona através de uma interface gráfica estática, implementada em linguagens php e html. Os acessos são efetuados somente através de linkagens internas, sem abertura a espaços virtuais externos. As turmas são criadas e gerenciadas por usuários com nível de administrador, que habilitam outros usuários com níveis de professor ou aluno. Porém, diante a crescente evolução e disseminação das ferramentas digitais, verificou-se a necessidade de adaptar o Planeta Rooda à nova tendência tecnológica da atualidade - o software social. Segundo Primo e Brambilla (2005) essa classificação constitui-se em um número de tecnologias empregadas para a comunicação entre pessoas e grupos por meio da Internet. Os autores ainda ressaltam que o suporte dado à interação, através dessas tecnologias, estimula que pessoas com interesses semelhantes compartilhem diferentes idéias. Desse modo, o software social também demonstra apoiar debates e negociação de diferenças, fatores importantes segundo Primo e Brambilla (2005).

Do ponto de vista educacional a concepção do software social é apoiada pela teoria construtivista de Piaget (1990), na qual a construção do conhecimento ocorre através da interação sujeito-objeto. O conhecimento para Piaget (1990) resulta das interações que se produzem a meio caminho entre o sujeito e o objeto, envolvendo uma dupla construção progressiva - o sujeito age sobre o objeto ao mesmo tempo em que esse objeto oferece resistência à sua ação. Esse objeto, por sua vez, pode ser um livro, brinquedo, vídeo, som, utensílio doméstico, software; outro indivíduo (colegas, familiares, professores) ou ainda objetos culturais como revistas, televisão, músicas, entre 
outros. É através da interação sujeito-objeto que o indivíduo constrói conhecimento. Desse modo, o conhecimento não nasce com o indivíduo, nem é fornecido gratuitamente pelo meio social. O sujeito constrói seu conhecimento na interação com o meio físico e com o meio social (Becker, 2007). Esse processo de construção de conhecimento Piaget (1974) denomina aprendizagem. Porém a teoria construtivista de Piaget (1990) algumas vezes é mal interpretada. Não significa que o aluno deva "aprender sozinho", mas sim encontrar liberdade para que ele, a partir da interatividade com o material disponibilizado e da interação com colegas e professor, construa as suas próprias conclusões. Por isso a importância da utilização de ambientes virtuais de aprendizagem na sala de aula. Ele possibilita a exploração crítica, investigativa e criativa do aluno sobre o conteúdo estudado.

Portanto, a remodelação do AVA Planeta Rooda, visa realizar as adaptações e reformulações necessárias para contemplar as características e funcionalidades do software social. O objetivo é de possibilitar aos seus usuários o desenvolvimento de habilidades identificadas por Veen e Vrakking (2009) como emergentes na geração digital:

Habilidades Icônicas - possibilitar que o aluno reconheça e interprete informações de caracteres icônicos (cores, ícones, símbolos) além dos semânticos (textos, discursos verbais). A interpretação icônica somada à semântica auxilia no desenvolvimento de outra habilidade - de saber discernir entre a informação interessante e a superficial, a confiável e a duvidosa.

Habilidade de executar múltiplas tarefas - Apoiar, através do acesso simultâneo a várias tecnologias digitais, o desenvolvimento da habilidade de prestar a atenção em várias fontes de informação simultâneas. Segundo Veen e Vrakking (2009), essa ação torna-se possível quando o aluno aprende a intercalar o nível de atenção entre as fontes ao mesmo tempo em que mantém um nível básico com todas.

Habilidade de Zarpear - Os autores Veen e Vrakking (2009) consideram zarpear o ato de alternar entre tecnologias, referindo-se em especial à troca de canais de televisão. Ao contrário de tentar vencer o tédio, para a geração digital zarpear é a capacidade de processar informações audiovisuais descontínuas e de construir um todo significativo de conhecimento. Portanto, zarpear torna-se uma alternativa importante, desenvolvida pelos nativos digitais, para evitar perder-se na riqueza proporcionada pelas informações disponíveis na atualidade.

Habilidade do comportamento não-linear - Atualmente realizam-se buscas na internet através de palavras-chave como assunto, título, entre outras, prática que também é possibilitada em artigos e demais textos digitais através da ferramenta "localizar nesta página". Segundo os autores a atividade de busca acarreta o desenvolvimento de subhabilidades, como a reflexão prévia sobre os objetivos da busca e a relação deles com a tarefa a ser realizada. Além disso, desenvolve a capacidade de criar estratégias de ação, abordando uma aprendizagem ativa e crítica.

Habilidades Colaborativas - Essas habilidades são bastante desenvolvidas através dos jogos de computador. Segundo Veen e Vrakking (2009) a ultrapassagem de certos níveis desses jogos é praticamente impossível sem o trabalho colaborativo. Desse modo, o usuário acaba desenvolvendo tanto estratégias individuais (competitivas), quanto 
estratégias colaborativas (em grupos). As habilidades sociais também são abordadas. Vínculos são construídos entre jogadores, muitas vezes extrapolando os limites do mundo virtual através de reuniões presenciais.

Portanto, a partir das possibilidades pedagógicas que a aplicação das ferramentas digitais propicia e, em especial, o software social, atualmente encontra-se em elaboração a reestruturação do Planeta Rooda. O objetivo é de apoiar o perfil da geração digital e possibilitar o desenvolvimento dessas novas habilidades emergentes na era digital. $\mathrm{O}$ processo de reestruturação e construção do novo Planeta Rooda 2.0 é abordado nas seções a seguir.

\subsection{Estudos necessários para a construção do Planeta Rooda 2.0}

O Planeta ROODA 2.0 objetiva, a partir dos conceitos da Web 2.0, incorporar uma nova concepção de ambiente virtual de aprendizagem. Desta forma, ultrapassa o paradigma do simples repositório de materiais didáticos, construindo uma ferramenta baseada na interação, socialização e na construção compartilhada do saber. Apropria-se de recursos digitais similares aos aplicados em plataformas da atualidade como o Orkut, Second Life, entre outros.

Devido à caracterização da plataforma, optou-se por manter a metáfora já utilizada no Planeta ROODA (figura 2). Essa se baseia no conceito de Space Opera (Novela Espacial), como os cenários cinematográficos de Star Wars e Star Trek, ou dos desenhos animados Cowboy Bebop e Star Blazers.

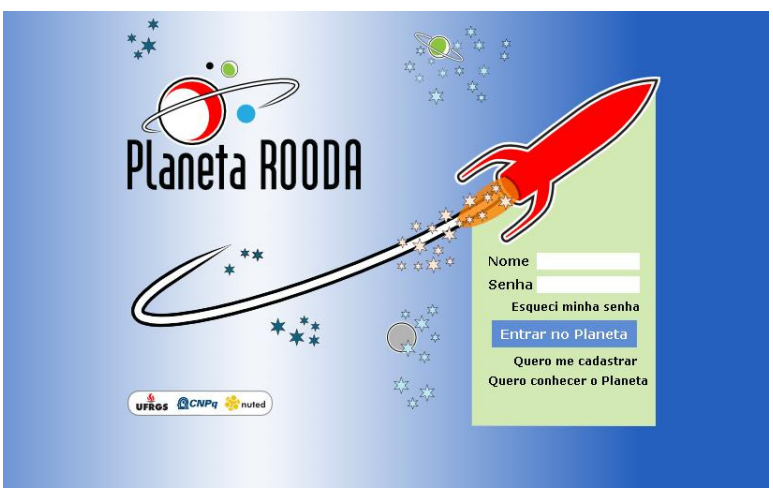

Figura 2 - Tela de login do Planeta ROODA 2.0

A adoção de avatares (figura 3) permite a projeção do aluno no referido ambiente, colaborando, inclusive, na conquista de uma maior afetividade na relação homemmáquina do mesmo. A partir da comunicação entre professores e alunos de diferentes turmas, possibilita um ensino interdisciplinar, fornecendo maior liberdade às dinâmicas pedagógicas aplicadas ao AVA. Na manipulação de cenários em tempo real, aproxima os usuários da metáfora aplicada, assim como também facilita o entendimento e a utilização das suas funcionalidades e dinamiza a interação entre usuários. Através da configuração de elementos dos ambientes pelos usuários, o Planeta ROODA 2.0 possibilita a personalização, colaborando na identidade do aluno com cada um dos ambientes.

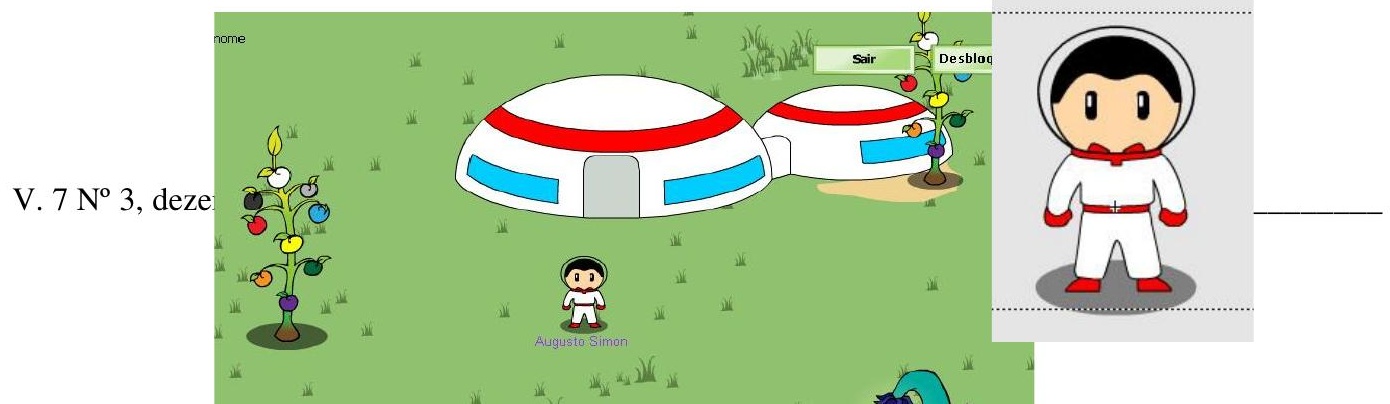


O planejamento do novo ambiente (figura 3) baseia-se na teoria dos multiversos (Melo, 2003), que consiste na existência de universos virtuais dentro de outros universos virtuais com autorizações herdáveis. $\mathrm{O}$ acesso ao mesmo ocorre inicialmente através de um administrador, que é nomeado durante a instalação do sistema. Ele é o responsável pelo controle e personalização dos ambientes dessa plataforma, através do Módulo de Construção do ambiente. O Módulo permite a inserção de objetos pré-definidos contendo as ferramentas do Planeta, fornecendo conteúdo ao seu ambiente. Após essa primeira etapa, ele poderá criar um ou mais universos vinculados ao seu de origem. Nesses outros universos há outros administradores, cadastrados e inseridos pelo primeiro. Cada um desses administradores do multiversigł como conceder outros universos a outros usuários cadastrados. No entanto, ele nunca poderá alterar o ambiente de onde derivou a não ser que essa autorização lhe seja fornecida pelo dono do ambiente, que por sua vez poderá alterá-lo conforme necessário. Esse vínculo é passado aos universos posteriormente criados, ou seja, o administrador do primeiro universo será também o administrador do segundo universo gerado através do primeiro e também do terceiro gerado através do segundo e assim sucessivamente. Os outros níveis administrativos são: coordenador, supervisor, professor e aluno, também herdáveis. Assim, cada nível inferior não tem permissão de alterar as ações dos superiores, sendo limitado por estes. Os usuários que não forem classificados por esses níveis serão considerados visitantes, podendo somente trafegar entre os universos e ter acesso aos objetos distribuídos nesses ambientes (a critério do administrador), sem possuir ferramentas de edição.

As interfaces e interações estão sendo programadas e executadas em Flash, através de objetos gráficos e programação ActionScript. Os dados são requisitados à programação PHP, que busca as informações no banco de dados MySQL, devolve ao PHP e este informa as alterações ao ActionScript. A maioria dos ambientes serão visualmente em 3D, de modo a possibilitar ao aluno a livre navegação pelo espaço virtual. Ela será possibilitada através da manipulação do seu avatar. Locais anteriormente estáticos como o planeta pergunta e planeta arte, entre outros, nesta nova versão serão abordados sob a forma de ambientes 3D.

\section{Desenvolvimento Tecnológico do Ambiente}

O desenvolvimento tecnológico do ambiente virtual de aprendizagem Rooda está sendo realizado pela equipe do NUTED/UFRGS (Núcleo de Tecnologia Digital Aplicada à Educação). A equipe é composta por três setores: programação, pedagógico e design. Reuniões quinzenais e mensais são constantemente realizadas, justamente para que o planejamento técnico, gráfico e pedagógico ocorra de modo concomitante. O desenvolvimento técnico e gráfico da reestruturação do Planeta ROODA está sendo 
baseado nos estudos pedagógicos abordados nas seções anteriores, sendo dividido em 4 etapas, explicadas a seguir.

Primeiramente a equipe desenvolvedora voltou-se à aquisição de Conhecimento Técnico, na qual foi realizado um aprofundamento teórico sobre as tecnologias já utilizadas na versão anterior e previstas para o desenvolvimento do mesmo. Apesar do conhecimento prévio sobre lógica de programação e de algumas linguagens, como o Action Script, tornou-se necessário realizar um aprofundamento a respeito da utilização da linguagem de programação PHP e da linguagem de marcação HTML. A investigação sobre as possíveis formas de trabalhar com o sistema de banco de dados MySQL também mostrou-se importante. Num segundo momento, realizou-se o estudo do Projeto e documentação, ou seja, a leitura e interpretação dos arquivos que compreendiam a primeira versão do Planeta Rooda, inclusive com a documentação dos arquivos e códigos-fonte existentes. Nesse processo foram analisados arquivos de edição do FLASH, códigos em ActionScript 2.0 e em PHP. A partir do aprofundamento a respeito do sistema de armazenamento dos arquivos da primeira versão no servidor, voltou-se à etapa de sistema de Controle de Versões. Nela, percebeu-se a fragilidade dos arquivos antigos, assim como o fato deles encontrarem-se suscetíveis a problemas comuns de edição e gravação. Um dos procedimentos considerados de risco, por exemplo, foi o fato dos arquivos estarem sendo editados diretamente no servidor. Esse fato possibilitava a edição por vários programadores ao mesmo tempo, o que poderia ocasionar subscrições indesejadas e até mesmo perdas. Para resolver esses e outros problemas foi instalado no servidor um sistema de controle de versões (CVS) do tipo SVN (Subversion). Com ele, além da resolução da dos conflitos entre versões de arquivos, obteve-se uma forma de backup de materiais antigos. Desse modo, tornou-se possível a obtenção de todas as versões de um mesmo arquivo, uma vez gravados utilizando o SVN. A partir desse momento, partiu-se para o desenvolvimento dos códigos de programação.

O desenvolvimento do software foi estruturado por tarefas específicas e com certo grau de independência. Essas foram escolhidas buscando um nível de dificuldade gradual e tiveram suas prioridades acertadas de acordo com as necessidades da equipe pedagógica e com a produção da equipe do design. O nível gradual de dificuldade mencionado devese ao fato de que, como em muitas áreas, cada desenvolvedor incorporado a um projeto de software, já em andamento, precisa de um certo tempo de adaptação para acompanhar a sua produção e gerar seus próprios códigos fonte. Esse tempo, apesar de ser reduzido quando o desenvolvedor possui domínio sobre as ferramentas utilizadas, está relacionado à familiarização com os códigos fonte e à estruturação dos arquivos utilizadas pelo grupo desenvolvedor. Como esperado, as tarefas iniciais foram bem simples. Porém, ao longo do tempo, essas foram evoluindo, propiciando alcançar o domínio tecnológico do projeto, necessário como embasamento para iniciar a sua construção. Isso possibilitou estruturá-lo de maneiras mais eficazes e potencializá-lo, através de novas tecnologias. A fim de melhor descrever esta etapa, é possível dividi-la em sub-etapas, caracterizadas em algumas áreas específicas, como módulos que compõem o projeto tecnológico. As mesmas, contudo, não devem ser vistas como diferentes projetos e, salvo exceções, não fariam sentido fora deste contexto. Suas ordens correspondem à ordem em que as atividades foram iniciadas, mas durante o trabalho foi comum a transição entre uma e outra área. São elas: sistema físico, estruturação do software, estruturação do design, sistema de comunicação com o banco de dados e sistema de administração. 


\subsection{Sistema Físico}

Refere-se ao desenvolvimento do Avatar a ser inserido no Planeta Rooda 2.0. Portanto, o sistema físico consiste nos algoritmos que geram os movimentos do avatar, dos objetos e todas as leis físicas que coordenam os acontecimentos no AVA. Neste sistema estão contidas também soluções de problemas mais complexos, como os algoritmos aplicados para remeter o ambiente a uma interpretação em três dimensões (embora sejam utilizadas apenas ferramentas de desenvolvimento em 2D) e os algoritmos de colisões entre objetos que, por sua modularidade, podem ser aplicados em outros sistemas interativos, seguindo uma das importantes tendências no desenvolvimento de softwares atuais.

O objeto referente ao avatar é formado basicamente por quatro clipes de filme, cada um deles representando a locomoção do referido avatar em um distinta direção. $\mathrm{O}$ movimento do objeto é controlado pelo usuário, através do teclado e do mouse. Quando o software detecta que uma ou mais teclas direcionais estão pressionadas (no caso da utilização do teclado), além de deslocar o avatar na direção correspondente, o sistema seleciona o clipe de filme do objeto que deve ser exibido. $\mathrm{O}$ avatar pode se movimentar nas quatro direções cardiais e nas quatro colaterais (figura 4). Utilizam-se as quatro teclas direcionais do teclado para movê-lo nas quatro direções cardeais. As direções colaterais são obtidas pressionando-se as duas teclas, referentes à direção colateral desejada, conjuntamente. Por exemplo, pressionar a tecla direcional para cima faz com que o avatar se mova para o norte. Já pressionar conjuntamente a tecla direcional para cima e a direcional para a esquerda faz com que o avatar se mova para o noroeste.

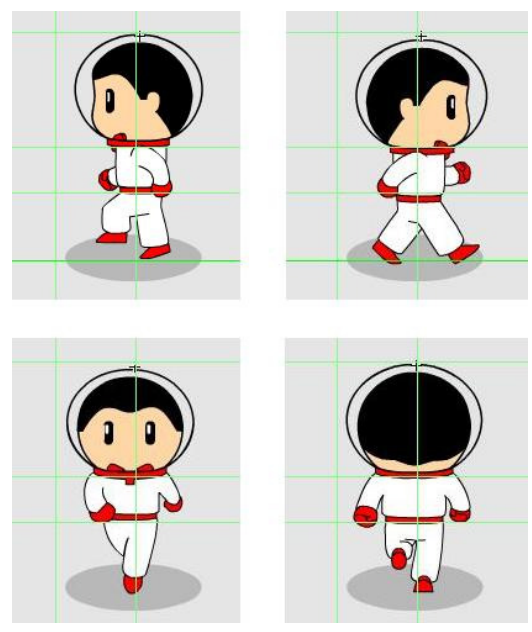

Figura 4 - Clipes de filme do avatar

No momento em que o avatar é movimentado, o software precisa lidar com três possíveis situações: o objeto do avatar será movimentado e o cenário, com todos os seus objetos, permanecerá parado; o objeto do avatar permanecerá na mesma posição, porém o software simulará sua movimentação movendo o cenário e todos os seus objetos; ou ainda, o objeto do avatar permanecerá na mesma posição, com o software simulando sua movimentação. Ressalta-se que, em todos os casos, o cenário e todos os objetos ficarão parados no momento em que o avatar esbarrar em algum outro objeto (outro avatar ou elementos do cenário). 


\subsection{Estruturação do Software}

Durante o período de desenvolvimento tecnológico, adotou-se uma política de estruturação dos códigos-fonte e arquivos constituintes do projeto. Os algoritmos foram separados por arquivos de código-fonte exclusivos, interligados pelo arquivo principal, visando suas funcionalidades e buscando maior eficiência de produção.

A modularidade das funcionalidades, como já salientado, é uma prática muito bem vista pelo programadores atuais e bastante incentivada. Ela ajuda a interpretação dos códigos-fonte, deixando os desenvolvedores mais ambientados com o código, facilitando a reutilização dos algoritmos em outros projetos ou funcionalidades.

\subsection{Estruturação do Design}

Todas as imagens e objetos, constituídos de gráficos ou clipes de filme, são desenvolvidos pela equipe de design. Após concluídos são enviados ao grupo de programadores, na forma de arquivos padrão do Flash, para serem incluídos no projeto.

Também nestes procedimentos de inclusão dos arquivos, procurou-se dar importância ao nível estrutural. Além dos objetos terem sido incluídos dentro do arquivo principal do $F L A S H$, foi criada uma pasta no servidor contendo todos os arquivos de forma independente.

\subsection{Sistema de Comunicação com o Banco de Dados}

Para um enfoque tecnológico, o software atual do projeto foi dividido em dois módulos distintos que se comunicam entre si. Um módulo é composto pelos arquivos desenvolvidos com o Flash e a sua linguagem de programação específica, o Action Script. Esse módulo, atualmente, é responsável pela interação do usuário com o AVA. É carregado na página do projeto, na Web, e não possui a capacidade de enviar e receber dados diretamente do banco de dados.

O segundo módulo, o qual este subitem descreve, é formado pelos arquivos desenvolvidos com o PHP e as linguagens de marcação. Sua função consiste em carregar no navegador o primeiro módulo citado e possibilitar a comunicação desse com o banco de dados.

Essa comunicação atualmente é realizada por um conjunto de algoritmos específicos, que podem ser vistos como um framework. Esse foi adaptado de um exemplo disponibilizado na Web e é adequado para controlar o envio e o recebimento de strings (conjunto de caracteres que se traduzem em informações) entre o módulo de interação e o sistema de banco de dados.

O framework descrito, entretanto, não é mais suficiente para o desenvolvimento do projeto. No estado em que se encontra, o módulo de interação necessita de um framework que o possibilite não apenas trocar strings com o banco de dados, mas sim outros formatos de informações que precisam ser armazenadas e obtidas do mesmo, e de forma rápida. Para tanto, está sendo estudado um novo framework de uso crescente e muito aconselhado atualmente na área, o AMFPHP. Resumidamente, trata-se de um conjunto de códigos de livre distribuição e uso genérico. Entre seus pontos fortes está a velocidade de transmissão de informações (pois as compacta), e a variedade de formatos possíveis para a troca dessas informações. O ponto negativo é que o tempo necessário para sua interpretação e adaptação ao projeto é extenso em relação às tecnologias já aplicadas. Essa tarefa foi parte do foco de desenvolvimento nos últimos dois meses de desenvolvimento e será um dos objetos de estudo da continuidade do presente projeto. 


\subsection{Sistema de Administração}

Será desenvolvido um sistema que possibilite que o usuário crie e edite, de acordo com seu nível hierárquico, os ambientes das turmas do Planeta ROODA 2.0. Essa edição compreende, entre outros aspectos, a organização visual dos ambientes da turma e a escolha das funcionalidades que estarão habilitadas na mesma. Embora já tenha sido amplamente discutido em muitas reuniões, a implementação do referido sistema de administração ainda encontra-se em andamento. Ainda que compreenda um elemento importante para o AVA, a sua ausência não impede a utilização do mesmo, o que diminuiu sua prioridade em relação às outras pendências. Enquanto ainda não é desenvolvido, é fornecida uma configuração padrão de turma para os usuários visitantes no projeto.

\section{Considerações Finais}

No início deste artigo foi verificada a relevância pedagógica da reestruturação da primeira versão do AVA Planeta Rooda, de modo a implementar recursos da Web2.0. Esses recursos, fatores que se destacam na inovação tecnológica presente no Planeta Rooda 2.0, foram possibilitados através de ferramentas de desenvolvimento de baixo custo financeiro, se comparadas com as utilizadas nos ambientes virtuais comuns da Web, como o Second Life e o World of Warcraft. A equipe que desenvolve o projeto aqui descrito, composta por bolsistas das áreas da informática, do design e da pedagogia, também é muito reduzida em quantidade e experiência técnica, tomando-se por referência as equipes que trabalham nesses mesmos exemplos.

Atualmente, o projeto ainda não permite a sua plena utilização e disponibilização. Todos os aspectos do seu desenvolvimento, citados nos itens anteriores, estão em fase de construção. Porém, a nova versão do AVA, o Planeta Rooda 2.0, aproxima-se de sua fase de testes com diferentes grupos de usuários, que não os próprios bolsistas. Esses grupos de usuários serão provenientes das instituições de ensino ligadas ao laboratório em que o projeto é desenvolvido, o NUTED/UFRGS (Núcleo de Tecnologia Digital Aplicada à Educação). Torna-se ainda necessário avanço em dois aspectos tecnológicos - o sistema físico e o sistema de administração. Desse modo, há a previsão de que os testes da nova versão do AVA com usuários externos ao núcleo desenvolvedor ocorram até o final deste ano de 2009. Portanto, prevê-se que até o final de 2010, o Planeta Rooda 2.0 esteja disponível para as instituições de ensino interessadas. Baseado na interação, socialização e na construção compartilhada do saber, o Planeta Rooda 2.0 objetiva colaborar na criação de novas práticas educativas, compatíveis com o perfil da geração digital.

\section{Referências}

BECKER, Fernando. Seminário A Formação da Função Semiótica: um estudo de fundamentação. Programa de Pós-Graduação da Faculdade de Educação da Universidade Federal do Rio Grande do Sul. Porto Alegre, $1^{\circ}$ semestre 2007.

BEHAR. Patricia A. Entrevista. 2007. Disponível em: $<$ http://www.aprende.com.pt/gca/?id=242> Acesso em 14/02/2009. 
MELO, Amanda M. Uma abordagem semiótica para o design de portais infantis com a participação da criança. Papirus: Campinas, SP, 2003.

PIAGET, Jean. Aprendizagem e conhecimento. Rio de Janeiro: Freitas Bastos, 1974. .Epistemologia genética. São Paulo: Martins Fontes, 1990.

PRIMO, Alex ; BRAMBILLA, Ana Maria. Software Social e construção do conhecimento. Redes Com, Espanha, n. 2, p. 389-404, 2005. Disponível em: <http://www6.ufrgs.br/limc/PDFs/softconhecimento.pdf>. Acesso em 14/08/2009.

VEEN, Wim; VRAKKING, Ben. Homo Zapiens: educando na era digital. Tradução Vinícius Figueira. Porto Alegre: Artmed, 2009. 